\title{
Absentee Parents in Disney Feature-length Animated Movies: What are Children Watching?
}

\author{
Monit Cheung ${ }^{1} \cdot$ Carol A. Leung ${ }^{2} \cdot$ Yu-Ju Huang ${ }^{1}$ (])
}

Accepted: 18 September 2021 / Published online: 2 October 2021

(c) The Author(s), under exclusive licence to Springer Science+Business Media, LLC, part of Springer Nature 2021

\begin{abstract}
Globally, Disney animated films integrate education into entertainment for families with children. This study uses the Social Capital Theory as the framework to support its focus on parental attention to children's developmental learning needs. This exploratory study examines how Disney animated movies over the last eight decades portraited parents in the life of the leading child characters. With three inclusion criteria (figure-length, animated, and at least one child being the protagonist), we found 155 films for the general audience released between 1937 and 2020. We read relevant website-posted plots and themes of each selected movie from three major informational websites. Data included the leading child, parents or parental figures, and the central theme of the movie. Most of these 155 stories $(n=97,61.3 \%)$ did not mention the child's biological parents. Half of the 48 parental-presence films projected life in a single-headed family and the main characters' heroic image. The movies released during 2000-2020 showed a higher parental presence than the previous seven vicennial periods. Findings show that families could use Disney animated movies illustrating fantasy and reality. Parents can engage children in discussions about friendship and family relationships after watching a movie. If children continue consuming Disney movies, parental involvement is needed to facilitate discussions of real-life learning to help children develop communication skills.
\end{abstract}

Keywords Parental inclusion $\cdot$ Heroic belief $\cdot$ Gender-based discussion $\cdot$ Single-headed families

As a classical icon, Snow White and the Seven Dwarfs was the first full-length animated feature produced by the Walt Disney Company in 1937. Since then, Disney animations have been a popular means to entertain and educate children. According to Nwokocha (2020), the top Disney movies to watch online globally during the first year of the COVID-19 pandemic were seven animated films: The Lion King (1994), Frozen (2013), Mulan (1998), Beauty and the Beast (1991), Snow White and the Seven Dwarfs (1937), Brave (2012), and Cinderella (1950 and 2015). In six out of these seven films (86\%), however, the main characters do not have parents present in the story.

Disney animated films with popular songs represent an educational means valued by parents and teachers (de Leeuw \& van der Laan, 2017). During the first few months

Yu-Ju Huang

mcheung@uh.edu

1 Graduate College of Social Work, University of Houston, 3511 Cullen Blvd, Houston, TX 77204-4013, USA

2 Department of Social Work, Azusa Pacific University, 901 E. Alosta Ave., Azusa, CA 91702-7000, USA of January 2020, when COVID-19 began to impact the world negatively, there was a monthly average of 94,000 search hits for The Lion King (1994), 69,000 hits for Aladdin (1992), 36,000 hits for Beauty and the Beast (1991), and 10,000 hits for Snow White and the Seven Dwarfs (1937) (MTS, 2020). These films' leading child characters have one or both parents being absent in their lives. In addition to these films, hundreds of other animated features are children's favorites, but parents are not the focus. We started to use the theoretical framework of parental involvement as social capital to formulate research questions to check if Disney animated films have mentioned the reasons behind why parents are absent in their stories.

\section{Parental Involvement as Social Capital}

As supported by the Social Capital Theory, parents' consistent presence in a child's life is essential to increase social capital for the family. McNeal (1999) used research data from parent-child discussions to support the correlation between children's academic outcomes and parental 
time commitment in parent-teacher organizations. Social capital in a family is a function of parental involvement to strengthen a child's cognitive and behavioral development. A part of this involvement becomes parental learning in achieving children's positive outcomes in education and selfefficacy (Cleland \& Lumsdon, 2021; Harding et al., 2015). With this framework, "parental presence" is a function of parents' participation in a child's daily activities with homebased support to promote the child's developmental needs. It stresses the importance of parental involvement in a child's learning. With this theoretical support, our study focused on parental presence in movies designed for children. Our questions are: To what extent do these movies describe parents' roles? Was it an increase in parental presence among the films between 1937 and 2000?

\section{Existing Analyses on Animated Films and Families}

Current literature has questioned the impact of superhero books on youth who experienced early parental loss (Betzalel \& Shechtman, 2017). Since Disney films play an essential role in children's learning process, critics voiced concerns that parents are often not portrayed in child-oriented movies. Some analyzed the content of Disney's animated films concerning its presentation of issues about social vulnerability about gender role differentials, and the races or ethnic backgrounds of the main characters. In a study by Faherty (2001), the top ten animated films described factors determining human diversities (cultural, ethnic, gender, and family structure) and many other social issues. Most issues were justice-related, concerning people with physical disabilities, speech impediments, intellectual disabilities, families living in poverty, and parents killed, incarcerated, missing, or dead. Another study focusing on 26 Disney animated classics and films in the early 2000s found four major themes: (a) strong family relationships, (b) diversity among families, (c) elevated father role and marginalized mother role, and (d) gender-based power differentials (Tanner et al., 2003). Some of these films provided information to help the audience appreciate individual differences and cultural diversities.

In discussing parenting roles, Brydon (2009) used Finding Nemo to illustrate how a father could play the "mothering" role without a maternal figure in the family. After observing many Disney movies, Boxer (2014) asked, "Why are all the cartoon mothers dead?" to examine a phenomenon faced by many famous Disney characters such as Ariel, Bambi, and Nemo. Boxer analyzed selected movies to describe a good father figure after the death of a nurturing mother. The analysis focused on the importance of the "fathering" shift away from the 'stepmother stereotype' presented in Disney's classic movies such as Cinderella. Nevertheless, the limited literature used popularity as the main criterion of film selection.

Disney's core value is to provide "family entertainment" through storytelling to "inform and inspire people around the globe" (Walt Disney Company, 2020b, Np). This value supported the intent of this present research to analyze if the information about the parents in the story could connect children to topics such as family relationships and protection. The analysis of the entire genre of Disney animated movies will help select suitable films for use in counseling to address how parents provide support and protection for the family and solve problems in times of despair.

\section{Method}

This exploratory study examines how Disney animated films over the last eight decades portraited the presence of parents in the life of the child characters. Parental presence is a phenomenon where one or both parents are physically present in the screenplay or mentioned in the movie. For example, in Sleeping Beauty (1959), Queen Leah, Princess Aurora's mother, is a minor character. The "parental presence" variable is coded as "mother, alive." In Frozen (2013), Anna and Elsa's parents died in an accident; again, in Frozen II (2019), a sunken ship reminded the audience the sisters' parents died at sea. The parental presence variable for both movies is identical: mother and father were mentioned but dead. Snow White and the Seven Dwafs (1937) has a stepmother because the biological mother passed. Even though the father is still living, he is not with the child. Thus, the parental presence code is "mother, dead" and "father, away." Since both parents are not present, they are "absentee parents."

Disney animated movies were the target due to this company's international popularity in moviemaking for children and families with the "widest age range in audiences" (Hubka et al., 2009) and family relationships as the theme (Tanner et al., 2003). The reason for selecting Disney as the analysis target was its mission to use movies as an educational tool to "inform and inspire people around the globe through the power of unparalleled storytelling" (Walt Disney Company, 2020b, web page).

Data collection took three steps. The first was an exhaustive search of Disney animated movies through three internet websites: Disneyanimation.com, Movies.disney.com, and Wikipedia.org. We provided research training for an assistant who helped with data collection. Our assistant identified 155 
Disney animated movies that fit the inclusion criteria (the protagonist is a child, the movie is feature-length, and an animated film released for the general audience). A feature-length film must be longer than 40 min (British Film Institute, 2020). These movies started from having sound and color to the most recently released (see Table 1). Those films marked with an asterisk are 58 sequels of previously released movies with a new screenplay.

The second step was to use these websites to identify the names of the leading child characters and whether their parents were present (in the movie or mentioned as alive) or absent (mentioned but died or away or not mentioned). Since previous literature analyzed only a few Disney films, the final step was to use the entire collection within the past eight decades to determine the trend of absentee parents in the movies. This analysis is a visualization method to show this trend over the past 80 years.

Our research notes contained measures to operationalize three variables. The first was the "age of the film," i.e., the number of years between the release year (of the film) and 2020 (data collection year). The second was the "parental presence" variable in four nominal categories: 1) both parents are present in the movie (or mentioned alive), 2) only one parental figure (mother or father) is absent, 3) absence of both parents either by death or being away, or 4) no mention of parents in the movie. The third variable was the "proportion of films with absentee parents," calculated by the number of movies without parents (category 3 and category 4 ) divided by the number of films in the decade.

\section{Data Analysis}

The data sources identified 155 Disney animated featurelength films released between 1937 and 2020. The research question is: How do Disney animated films portray the main child character's parents in the stories? If parents are absent in a selected film, a follow-up question could be: Does the movie provide information about the causes for absentee parents? SPSS 26 was the statistical software for descriptive and bivariate analysis. Table 1 shows data listed by the featured films by title, movie length, main characters, the leading child's biological parents, and the primary theme described in the cinematic plot. The assistant used keywords ("movie name," theme or moral, or purpose) to search the internet to find the primary theme for each movie. We checked all movie descriptions from the internet with the exact keywords and watched 35 free-access films (over 20\%) to ensure data accuracy and trustworthiness for further analysis. Since the information collected for this study came from secondary sources (movie websites and publicly accessible films), this study does not involve human subjects. Therefore, research ethics reviews are not required.

\section{Results}

\section{Increase in Animated Movie Production}

Table 1 lists 155 movies released between 1937 and the first quarter of 2020-a history of 83 years of Disney animated feature-length film production in colors and with sound. The average length of these films was 84.86 min (Median $=82$, $S D=16.7)$. The shortest movie, Saludos Amigos (1943; $42 \mathrm{~min}$ ), was a viral-cartoon cinematic movie. In comparison, the longest movie, Bedknobs and Broomsticks (1971; $139 \mathrm{~min}$ ), was a "live-action plus animated" fantasy film that integrated cartoon technology into a human-acting movie. There were 27 (17.4\%) releases between 1937 and 1979 (annual average $=0.64$ movies) less than one movie per year) and $128(82.6 \%)$ releases between 1980 and 2020 (annual average $=3.2$ movies).

Figure 1 shows the growth of feature-length animations primarily released in the last two decades (2000-2020). The most recent two decades had more films than the previous vicennial. At mid-point, there were 78 releases between 1937 and 2002 in 65 years and 77 releases between 2003 and 2020 in the most recent 18 years. Comparing these two groups of films (1937-2002 vs 2003-2020), the percentages of films having absentee parents (70\% vs $68 \%$ ) or not $(30 \%$ vs $32 \%$ ) showed no statistical significance, $\chi^{2}(1)=0.161$, $p=0.688(v=0.0065)$. This statistic shows the absenteeparent phenomenon happened regardless of time.

\section{Increase in Parental Presence}

Among the 155 films, the majority $(n=97,62.6 \%)$ did not mention the leading child's parents in the story. Only 24 movies (15.4\%) presented information about both parents. For example, at the beginning of Mulan (1998), both parents were briefly there to set the stage before Mulan leaving to join the national army in China. Eight films (5.1\%) explicitly described both parents were dead or away. In 47 films (30.3\%) containing information about one parent, only 24 biological parents (11 mothers; 13 fathers) were present. For those child characters without parents, two had stepmothers: Snow White's stepmother (the "Evil Queen" Grimbilde) and Cinderella's "wicked stepmother" (Lady Tremaine); six had adoptive parents: Tarzan's adoptive mother (Kala, the gorilla) in Tarzan 1 and 2; Tod's adoptive mother (Widow Tweed) in The Fox and the Hound; Lilo's legal guardian (Nani, the sister) in Lilo \& Stitch 1 and 2; Kronk's adoptive parent (Yzma, the witch) in The Emperor's New Groove 2. None of these 155 films mentioned a stepfather. Among 40 films that mentioned one or both parents of the main child, 24 mentioned both parents alive, four mentioned the mother 


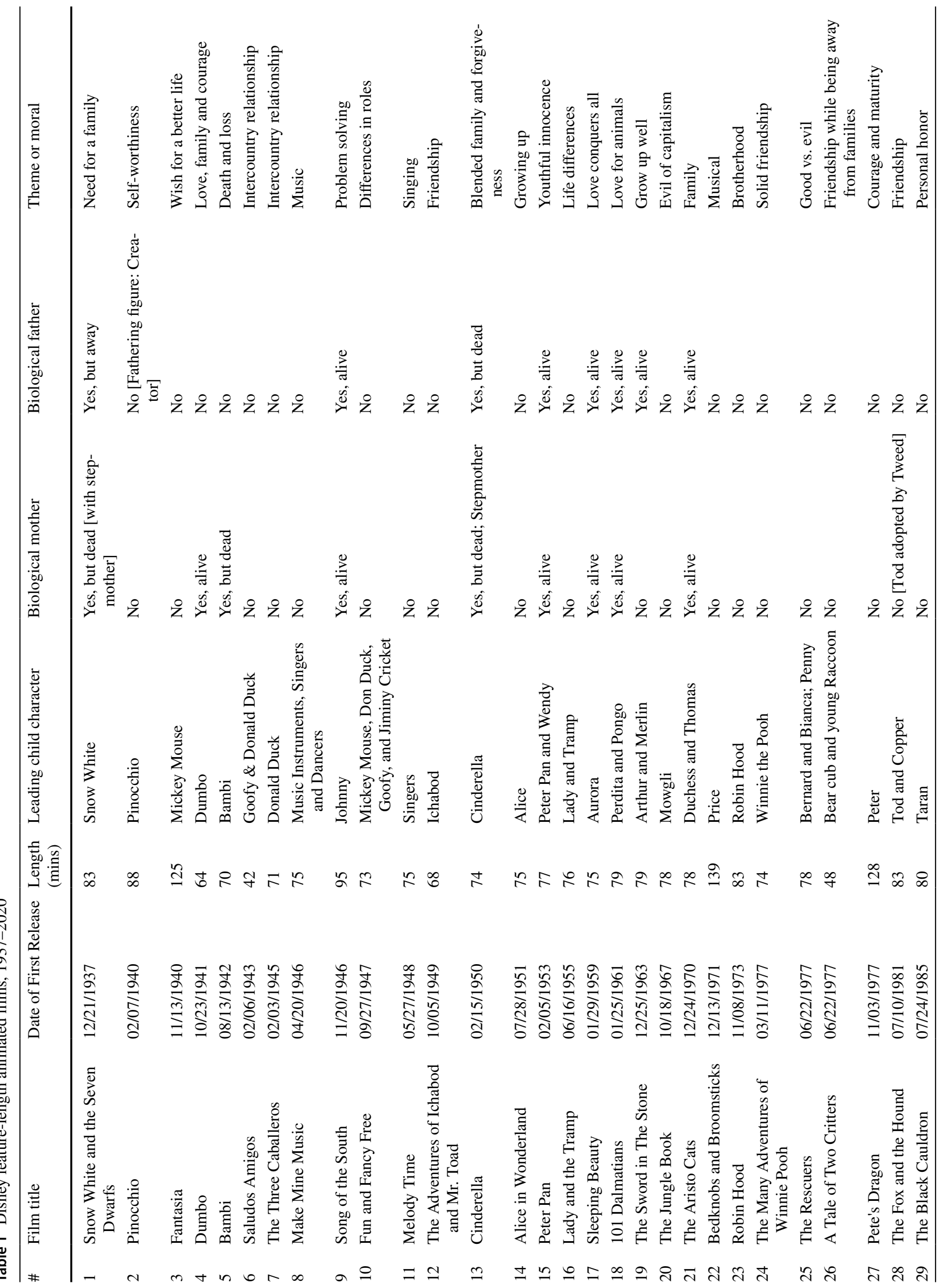




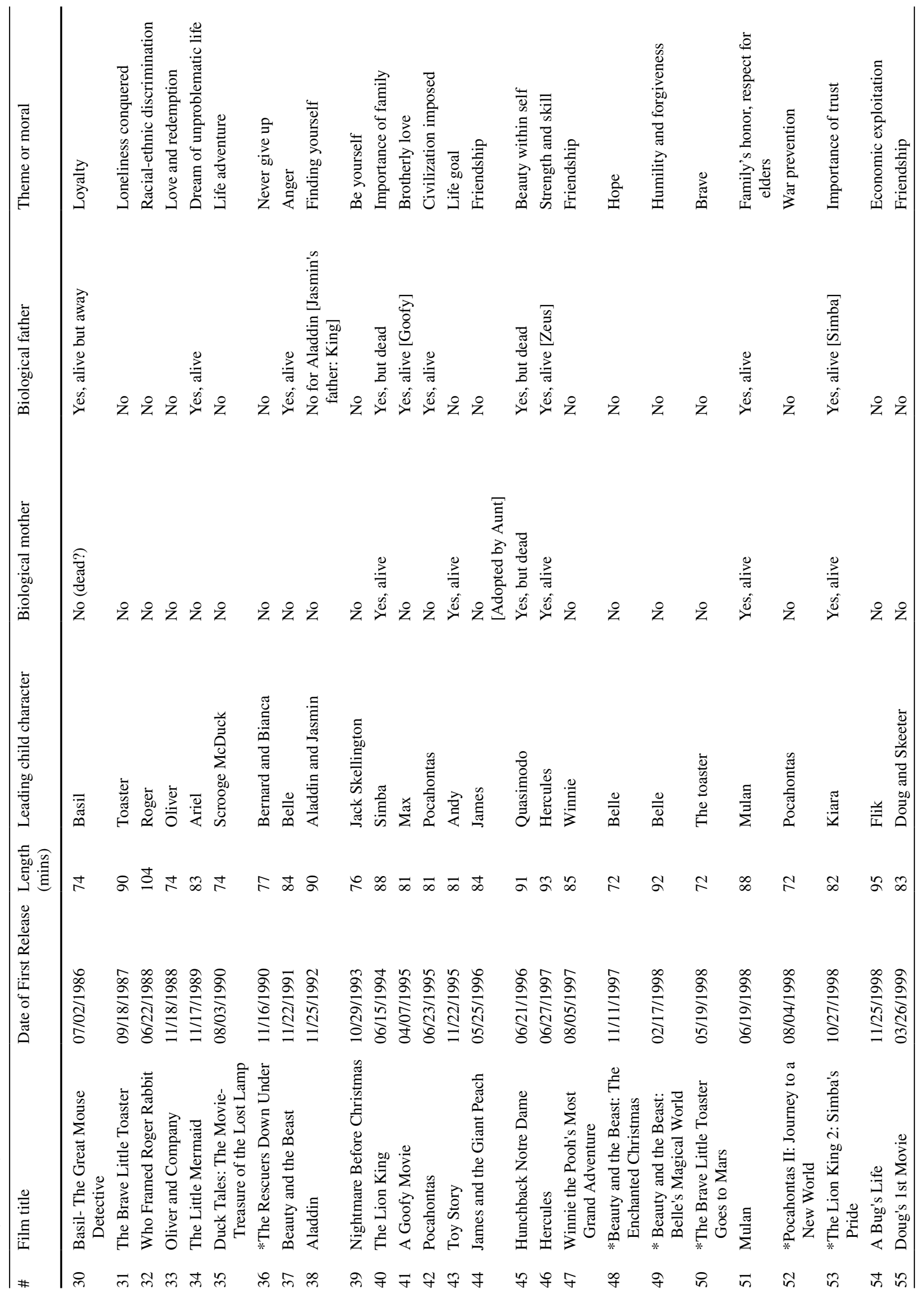




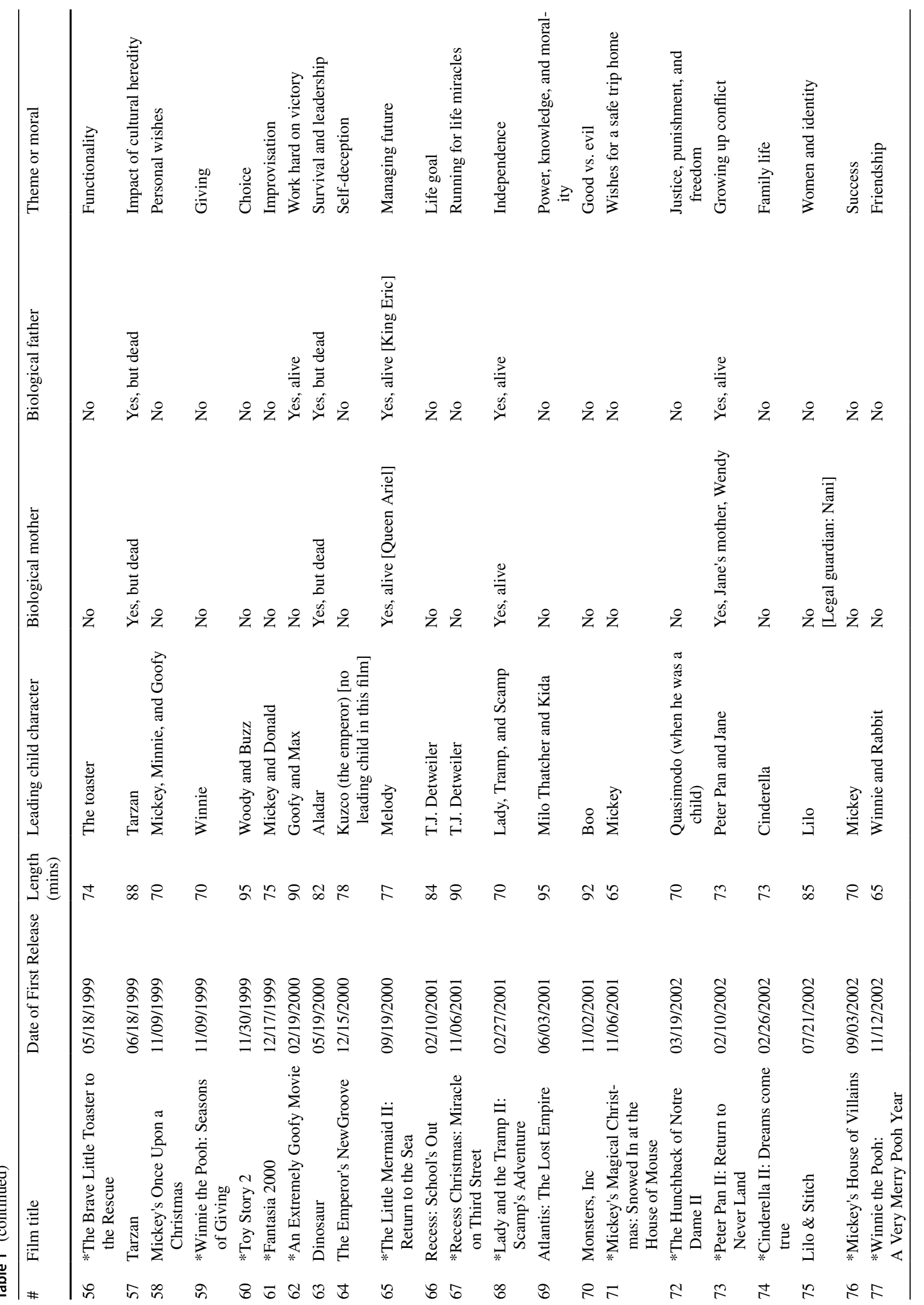




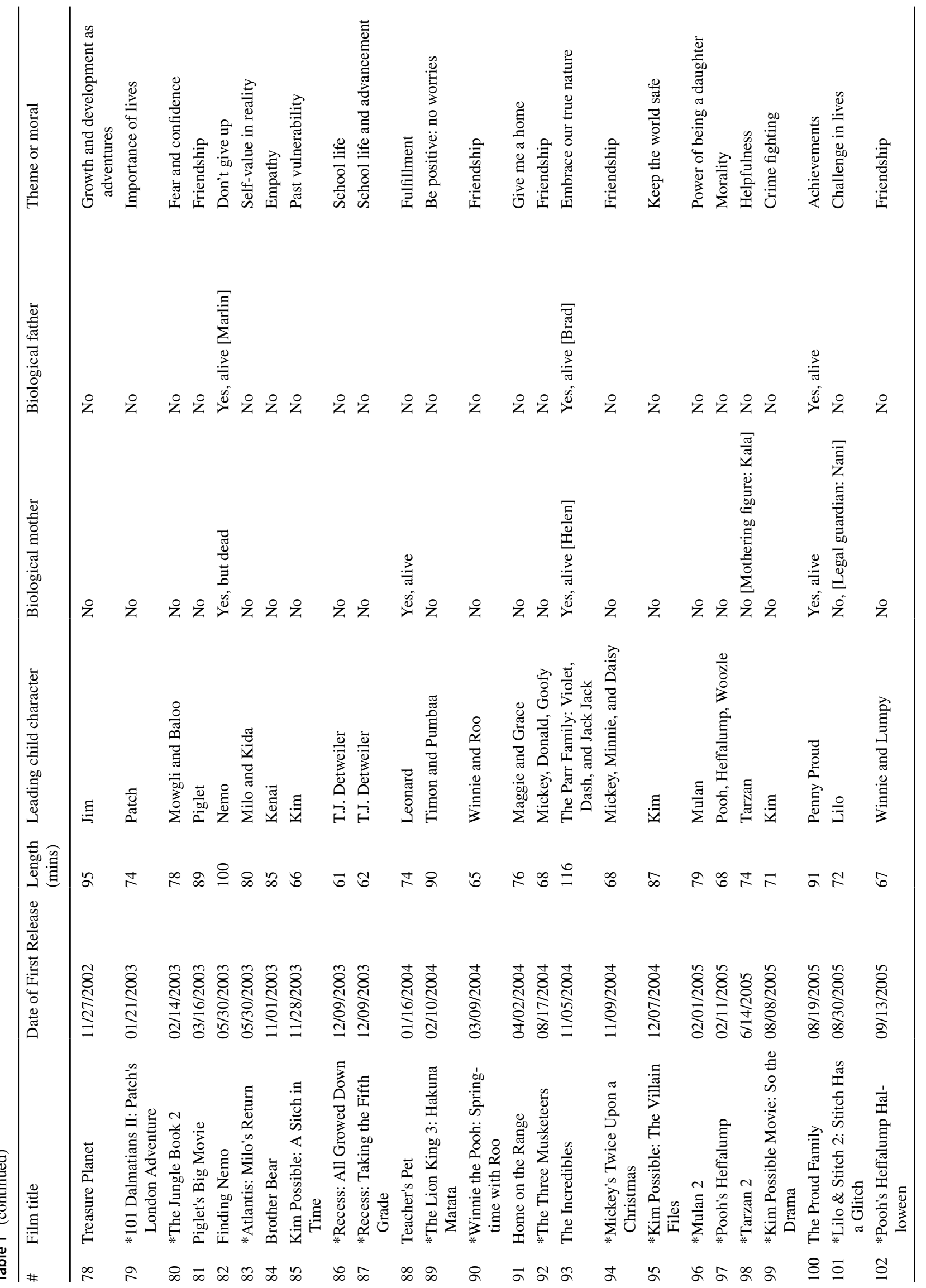




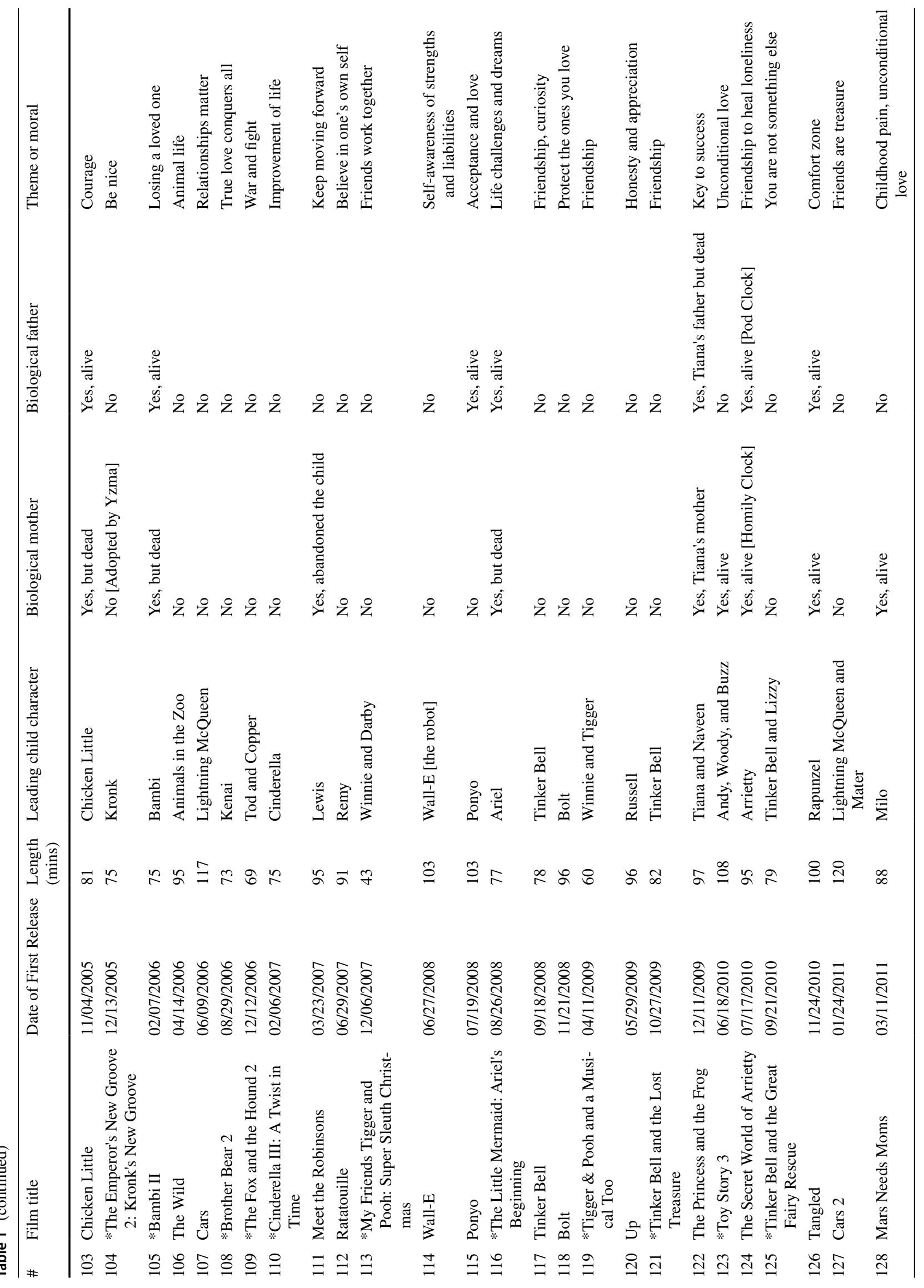




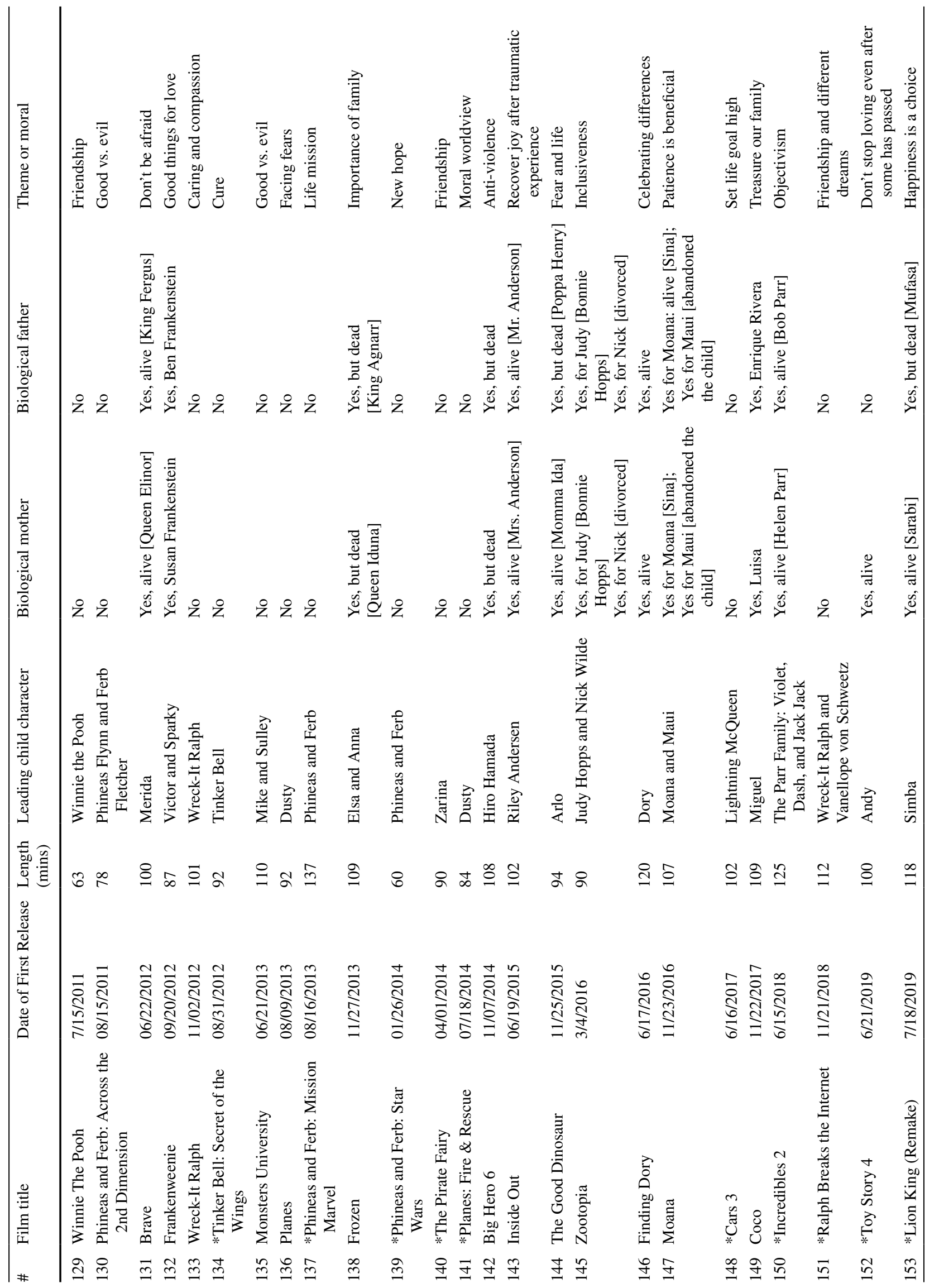




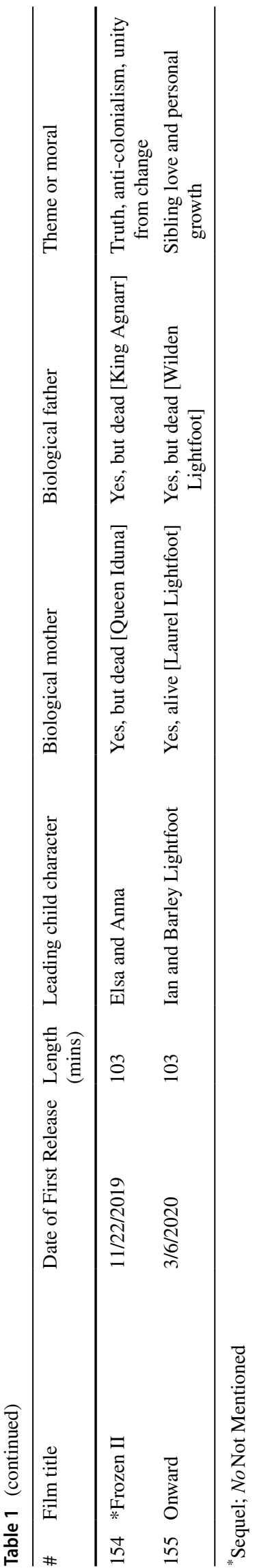

alive but not father, four mentioned only the father alive but not mother, and eight mentioned both parents died or were away. The statistic, $\chi^{2}(1)=10.975, p=0.001(v=0.0308)$, even with a small effect size, shows that a higher proportion (70\%) of the parents are there with the child. However, 75\% of these 155 movies did not mention parents in their plot. These are called the "no mention" cases.

Table 2 compares parental presence figures in the 155 films in the past eight decades (1937-2020). A significant finding is that Disney presented its effort to proportionately increase the presence of one or both parents to $57.6 \%$ in the most recent decade, comparing to $26.23 \%$ in its previous decade. Films within the immediate past decade (1-10 years ago) had shown an increased proportion (30.3\%) of "having both parents mentioned," $20.6 \%$ higher than the previous decade (11-20 years ago) of 9.7\%. Figure 2 produces a visual comparison between the proportions of parental presence and absentee parents over the eight decades. The ratio of having one or both parents presented in the story ranged between 15 and $65 \%$. It had an upward trend from the 1930s to the 1950s but dropped in the 1960s. When the child's biological parents are mentioned but absent in the story, the reasons are related to death, divorce, adoption, or child abandonment. It is the "no mention" cases responsible for most unknown causes of having absentee parents.

\section{Themes of the Movies}

Most movies $(72.9 \%, \mathrm{n}=113)$ share the message about loving self and others. Their themes are related to self-development $(n=33)$, friends $(n=24)$, life $(n=14)$, love $(n=13)$, family $(n=12)$, future solution and hope $(8)$, past and forgiveness $(n=4)$, grief and loss $(n=3)$, and school $(n=2)$. Other movies $(27.1 \%, \mathrm{n}=42)$ are associated to morality and social values, including discrimination $(n=11)$, good vs. evil $(n=7)$, handling emotions $(n=7)$, power $(n=5)$, intercountry relationships $(n=4)$, roles and functions $(n=3)$, music $(n=3)$, and culture $(n=2)$. These keywords from the descriptions of the movies showed both the micro and macro perspectives of humanity.

\section{Discussion}

A prominent finding in this study was a pattern of more animated films produced by Disney in the past two decades. The supply-and-demand market likely determined this increase when more moviegoers were young parents with children ages two to eleven (Pirnia, 2015). This finding provides three implications for family communication research. First, the fact that children are the primary consumers leads to the main focus on children themselves. It is not surprising to find the recent movie design suits the child's interest and 
Fig. 1 Disney animated films: 1937-2020

Table 2 Mention of parents in Disney animated films: 1937-2020

Fig. 2 Parental presence in Disney animated films: 1937-2020

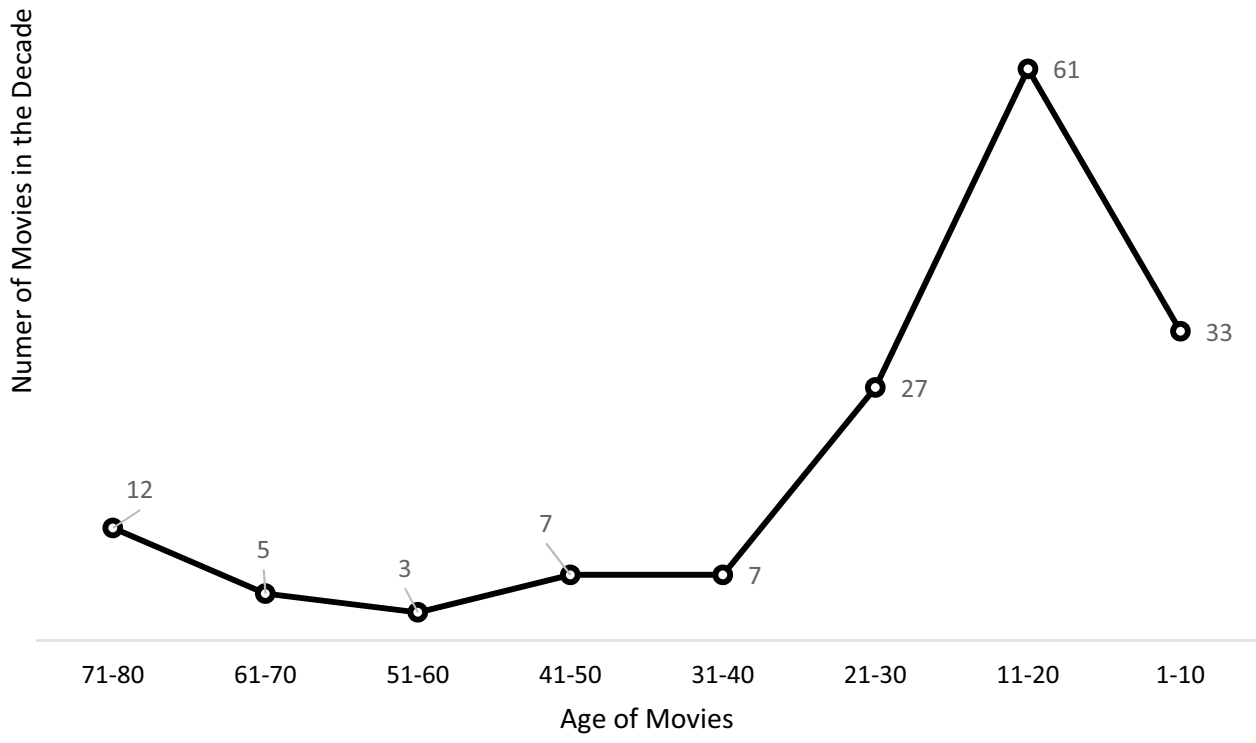

\begin{tabular}{|c|c|c|c|c|c|}
\hline \multirow[b]{2}{*}{ Age of films (Years ago) } & \multirow[b]{2}{*}{$\begin{array}{l}\text { Number of } \\
\text { films }\end{array}$} & \multicolumn{4}{|c|}{ Percentage within Decade } \\
\hline & & $\begin{array}{l}\text { No mention of } \\
\text { Parents }\end{array}$ & No parents & $\begin{array}{l}\text { Mention of } \\
\text { one parent }\end{array}$ & $\begin{array}{l}\text { Mention } \\
\text { of both } \\
\text { parents }\end{array}$ \\
\hline $71-80$ & 12 & $58.30 \%$ & $16.70 \%$ & $16.70 \%$ & $8.30 \%$ \\
\hline $61-70$ & 5 & $20.00 \%$ & $40.00 \%$ & $0.00 \%$ & $40.00 \%$ \\
\hline $51-60$ & 3 & $33.30 \%$ & $0.00 \%$ & $33.30 \%$ & $33.30 \%$ \\
\hline $41-50$ & 7 & $85.70 \%$ & $0.00 \%$ & $0.00 \%$ & $14.30 \%$ \\
\hline $31-40$ & 7 & $71.40 \%$ & $0.00 \%$ & $28.60 \%$ & $0.00 \%$ \\
\hline $21-30$ & 27 & $59.30 \%$ & $7.40 \%$ & $22.20 \%$ & $11.10 \%$ \\
\hline $11-20$ & 61 & $73.77 \%$ & $4.92 \%$ & $11.48 \%$ & $9.84 \%$ \\
\hline $1-10$ & 33 & $42.40 \%$ & $9.10 \%$ & $18.20 \%$ & $30.30 \%$ \\
\hline Total \# of Films & 155 & 95 & 12 & 24 & 24 \\
\hline$\%$ of Total & 100 & 61.29 & 7.74 & 15.48 & 15.48 \\
\hline
\end{tabular}

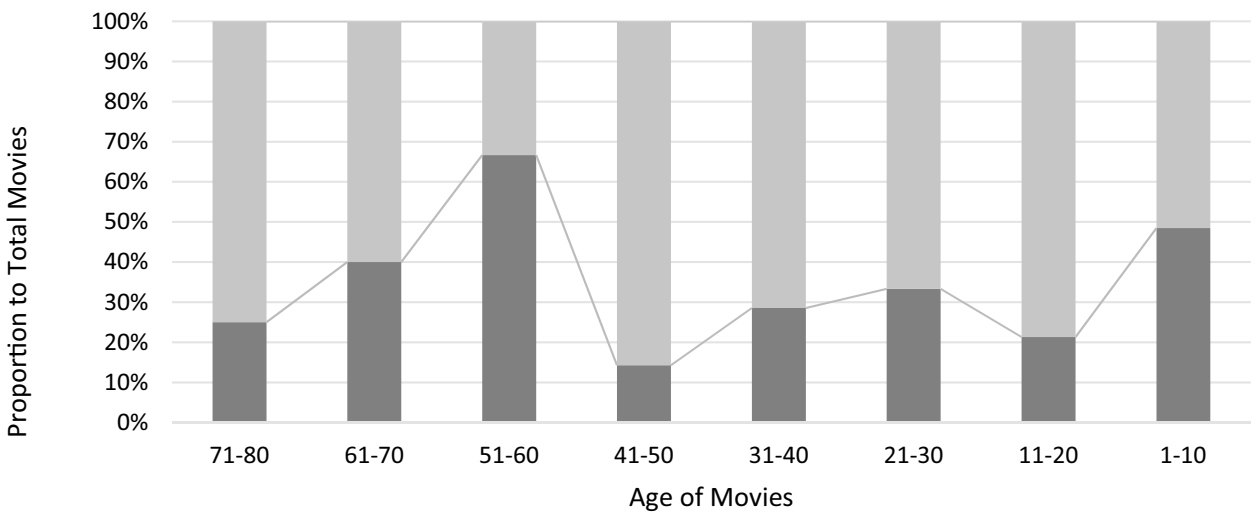

1 or 2 parents Absentee parents 
the company's core value of using creative technologies to improve the quality of family life (Walt Disney Company, 2020a). Second, the diversity-oriented content also fits the practice of social work for inspiring people to respect cultural diversity and social values of respecting others. Children need guidance to learn about diverse family structures in society. They also need parental support to feel safe in their environment. Diversity and safety are two concepts for parents to share with their children. Third, caregivers could use the content to educate children about unfair situations in society and acceptance of differences. When children have achieved a high level of acceptance, they become more empathic toward other people's misfortune, such as losing a parent or a home or living in a substandard situation without parental support.

Like any fairytale, Disney movies mix fantasy with reality. However, many well-intended films may have overemphasized the heroic aspect onto a person and enforced gender role stereotypes (Bahn et al., 2019; Zurcher et al., 2020). For example, the movies released 50 years or more ago, girls and women were the victims waiting for a male rescuer. These fairytales are still popular today, but they have been rooted in many princess characters with ideals leading to a happy ending (Hefner et al., 2017). Colette Dowling (1981) analyzed the "Cinderella complex" (as illustrated in Agatha Christie's (1955) detective story Hickory Dickory Dock) to demonstrate how women's "fear of independence" has been learned in their socialization process since childhood. Parental engagement in a child's learning journey would help children discuss differences between fantasy and reality. Children could share viewpoints about any misrepresented information and discuss adjusting the story to enhance cultural sensitivity.

It is also important to note that children may believe certain movies are acceptable in real life in their early learning stages. For example, Cappiccie et al. (2012) applied the basic principles of the critical race theory to analyze the characters in three popular Disney animated films to illustrate the most pervasive forms of racism and micro-aggression. These films are The Lion King (background in Africa), Mulan (in China), and Pocahontas (about an indigenous people). As case examples, these films with content analysis results could be teaching tools for facilitating discussions on cultural stereotypes, societal role distortion, and racism (Bazzini et al., 2010; Hefner et al., 2017). These films' main characters could be advocates of social justice and role models in leadership. They could be a voice for children to talk about any concerns they have experienced in their surroundings. With racism embedded in the movies, social workers could work with parents to address how animated films could be a tool for discussing the impact of stereotypes on the perception toward oneself and others. These discussions could demonstrate the achievements of equity and fairness in different environments.

Compared to the findings by Bahn et al. (2019), who studied family stereotypes and family caregiver characteristics as portrayed in Disney films from 1937 to 2016, this study supported the implications related to providing adequate guidance for children when they have questions about these crises or other similar situations that they encounter. Serving as a child's guardian involves knowing what children are doing and being knowledgeable about the contents of what children are watching. Each movie has a moral behind the story. Instead of prohibiting children from watching these movies due to implicit biases, parents could guide children to project learning about changing the story to achieve happiness, respect, successful life goal and handling situations through a nonjudgmental lens.

\section{Implications to Parent-Child Communication}

A limitation of this study was the sole use of Disney animated films in the analysis. There are other animated films and family movies that could provide alternative viewpoints for further analysis purposes. Since families play an essential role in these stories for children, parents could discuss what their children expect to learn from these movies. At the same time, children could talk about perceptions about the families in the movies. With the trend that more parents are present and mentioned in the most recent films, the implication of this study included the value of applying these movies in parent-child communication in five areas:

(1) Know that there are diverse family structures;

(2) Express from the consumer's point of view the need for family entertainment to provide a healthy balance on what children could and should learn from;

(3) Address equitable solutions while presenting unfairness in life;

(4) Remove aggression, biases, and implicit discrimination;

(5) Use relevant movie clips to help parents think about alternative questions or retell stories to handle personal struggles due to racial and cultural differences.

Another limitation is related to the measure of "absentee parents." When parents are absent due to "no mention," we could only code the parental presence variable as "absence." With no explanations in the movie, some children may wonder why the parents are not there to help. Social workers could use animated films to develop case scenarios for parents to create a question-and-answer list when dealing with the child's concerning "no parents" being there. Based on these five discussion areas, the following potential questions 
are recommended as examples to stimulate critical thinking and promote parent-child communication:

1) Knowledge assessment: If a problem happened in today's society, what would this child character ask their parents? In this family, who may have questions about this problem/sickness that has been going around?

2) Family-focused value: What would be different if you had the power to change a part (or the ending) of this movie? What strengths does this family have?

3) Fairness and equity: If the situation has changed based on the principle of justice, what would people in this story have done differently? What would you suggest the parents do if they were present in this movie?

4) Family and social support: What support would this child need if this unjust situation continues? Who could help you stay calm if you were the child in this story?

5) Search for alternatives: What did this story tell you about safety (health or wellbeing)? Who would provide comfort for the child character in this story if the problem came back?

\section{Conclusion}

This study found that Disney animated films historically have not focused on the entire family unit, mainly by not having the main child character's parents present in the story. New changes have been found in the past decade that parents became more visible in these films. Disney movies being child-focused with families in the background is an understandable approach. This understanding is similar to an explanation by Charles Schulz, creator of Peanuts, who attributed his work to the adults not visible in his cartoon strips. Except saying "mwa-mwa," Schulz said, "[adults] wouldn't have room to stand up [in the] only an inch and a half high" daily strip (McCann, 2019, web page). Similar to Schulz's idea of creating a child-friendly environment without the presence of adults, many Disney movies apply the psychology of this comfort zone to help children address learning reflections and talk about their ideal perspectives. With parents in the background in the film and as an audience, Disney animated films can be suitable for children learning from the perspective of other children of how they deal with life crises. Parents develop questions to ask children about their definition of a crisis. Based on the case examples generated from these movies, parents could hear potential questions children may ask if they are distressed about the situation faced by the child characters. In parallel, counselors who work with parents can also serve as life coaches to help parents use appropriate means to communicate with children about their curiosities and concerns.
Acknowledgements The authors wish to thank Ms. Gladys Chan, a Disney movie consumer, for her helpful insight into the data collection process.

\section{Declarations}

Conflict of interest The authors of this article declare no conflict of interest in submitting this article to this Journal. This study uses internet websites to collect data; no human subjects are involved, and no informed consent procedure is necessary.

\section{References}

Bahn, G. H., Lee, S. Y., Hong, M., \& Lee, Y. J. (2019). Characteristics of caregivers in Disney animations. Psychoanalysis, 30(2), 25-31.

Bazzini, D., Curtin, L., Joslin, S., Regan, S., \& Martz, D. (2010). Do animated Disney characters portray and promote the beauty-goodness stereotype? Journal of Applied Social Psychology, 40(10), 2687-2709. https://doi.org/10.1111/j.1559-1816.2010.00676.x

Betzalel, N., \& Shechtman, Z. (2017). The impact of bibliotherapy superheroes on youth who experience parental absence. School Psychology International, 38(5), 473-490. https://doi.org/10. $1177 / 0143034317719943$

Boxer, S. (2014). Why are all the cartoon mothers dead. The Atlantic, July/August, 96-106.

British Film Institute. (2020). Feature length? https://www2.bfi.org.uk/ archive-collections/bfi-filmography-faq.

Brydon, S. G. (2009). Men at the heart of mothering: Finding mother in Finding Nemo. Journal of Gender Studies, 18(2), 131-146.

Cappiccie, A., Chadha, J., Lin, M. B., \& Snyder, F. (2012). Using critical race theory to analyze how Disney constructs diversity: A construct for the baccalaureate human behavior in the social environment curriculum. Journal of Teaching in Social Work, 32(1), 46-61. https://doi.org/10.1080/08841233.2012.640252

Christie, A. (1955). Hickory dickory dock. UK Crime Club Choice.

Cleland, J., \& Lumsdon, D. (2021). How can school-parental participation support the generation of social capital for parents? Educational \& Child Psychology, 38(2), 19-39.

De Leeuw, R. N. H., \& van der Laan, C. A. (2017). Helping behavior in Disney animated movies and children's helping behavior in the Netherlands. Journal of Children and Media. https://doi.org/10. 1080/17482798.2017.1409245

Dowling, C. (1981). The Cinderella Complex: Women's hidden fear of independence. Simon \& Schuster.

Faherty, V. E. (2001). Is the mouse sensitive? A study of race, gender, and social vulnerability in Disney animated films. Simile, 1(3), no pages.

Harding, J. F., Morris, P. A., \& Hughes, D. (2015). The relationship between maternal education and children's academic outcomes: A theoretical framework. Journal of Marriage \& Family, 77(1), $60-76$.

Hefner, V., Firchau, R., Norton, K., \& Shevel, G. (2017). Happily ever after? A content analysis of romantic ideals in Disney princess films. Communication Studies, 68(5), 511-532.

Hubka, D., Tonmyr, L., \& Hovdestad, W. (2009). Social work and child maltreatment intervention in Disney animated feature films: 1937-2006. Australian Social Work, 62(1), 99-112.

McCann, E. (2019). 20 surprising facts about Peanuts and its creator Charles Schulz. Ranker. https://www.ranker.com/list/peanuts-charl es-schulz-trivia/erin-mccann.

McNeal, R. B., Jr. (1999). Parental involvement as social capital: Differential effectiveness on science achievement, truancy, and 
dropping out. Social Forces, 78(1), 117-145. https://doi.org/10. 2307/3005792

MTS Staff Writer. (2020). Ranked: Most popular Disney classics in the USA. Marketing Technology Insights. https://martechseries.com/ technology/ranked-popular-disney-classics-usa/.

Nwokocha, A. (2020). The best Disney films to see during quarantine. The Spectrum. https://www.blakespectrum.org/blog/2020/05/16/ the-best-disney-films-to-see-during-quarantine/.

Pirnia, G. (2015). 1985: The last great year in the film for kids and young adults. The Atlantic, March 6. https://www.theatlantic.com/ entertainment/archive/2015/03/why-the-1980s-is-the-last-greatdecade-in-youth-films/385295/.

Tanner, L. R., Haddock, S. A., Zimmerman, T. S., \& Lund, L. K. (2003). Images of couples and families in Disney feature-length animated films. American Journal of Family Therapy, 31(5), $355-374$.
Walt Disney Company. (2020b). Social responsibility. https://thewa ltdisneycompany.com/social-responsibility/.

Walt Disney Company. (2020a). About the mission. https://thewaltdis neycompany.com/.

Zurcher, J. D., Brubaker, P. J., Webb, S., \& Robinson, T. (2020). Parental roles in "the circle of life" representations of parents and parenting in Disney animated films from 1937 to 2017. Mass Communication \& Society, 23(1), 128-150. https://doi.org/10.1080/ 15205436.2019 .1616763

Publisher's Note Springer Nature remains neutral with regard to jurisdictional claims in published maps and institutional affiliations. 